Society for the Anthropology of Work • Book Forum: Threshold

\title{
Domains of Indistinction
}

Ishani Saraf

Published on: Jul 05, 2021

License: Creative Commons Attribution 4.0 International License (CC-BY 4.0). 
In Threshold: Emergency Responders on the US-Mexico Border, Ieva Jusionyte expertly mobilizes work histories, daily itineraries, and remembered emergencies across the multiple worksites that she traverses. Her own training as an emergency worker provides insight into the affective commitments, situated knowledges, and practical dispositions drilled into the working body by anticipated and actual emergencies. Jusionyte recalls how, early on in her research, she and some of the emergency responders she came to know "walked up and down the neighborhood discussing techniques for breaking down different types of doors" (p. 26). This attunement to what she calls the "materiality of terrain" (p. 26) enhances the ethnographic attention she gives to spatial forces and relations, as the border produces both unique emergencies and particular forms of response entangled in multiscalar histories and politics of place.

In Nogales, Jusionyte provides a remarkable account of the changing materiality of the border fence and the injuries it inscribes on the bodies of migrants to the United States. For emergency responders, tending to these bodies is just one of the many variables they must attend to at the border as a milieu of public safety and security. Jusionyte's participation in training programs and drills at various places along the border provides a glimpse into the ever-evolving imaginary of threat produced by managerial logics and bureaucratic modes of speculation. It also reveals the wider political economy of "binational cooperation" (p. 179) that differentially distributes the tasks that make up emergency work, such as the provision of labor by Mexican personnel and technology and training by their U.S. counterparts. Yet Jusionyte also demonstrates how training and drilling can engender a sense of mutual aid and "brotherhood" (p. 89), and how stories of "uncanny coincidences" (p. 141) in which emergency workers face situations they have just trained for underscore the need to continuously renew their skills.

The last part of the book unfolds in remote areas of the desert, where fences and checkpoints concentrate border crossing activities. These spatial formations, Jusionyte argues, are part of the "tactical infrastructure" (p. 11) and "weaponized terrain" (p. 213) that produces intensified threat to specific lives. Through her time volunteering at the Arivaca Fire Department and at humanitarian aid agencies like the Tucson Samaritans, Jusionyte is able to describe the lives in relation to the bodies she is trying to stabilize, sometimes during long journeys from emergency site to hospital. It is here that she elaborates most forcefully the entanglements of violence and care at the frontier. Law, safety, and funding requirements increasingly push emergency 
responders to take on roles of immigration enforcement. While in urban Nogales the impetus to provide care to people regardless of their immigration status is voiced unequivocally, remote areas produce domains of distinction for those who receive care and domains of indistinction between those who provide care and those who enforce the law.

I was struck by Jusionyte's centering of emergency responders as "those who do the manual labor of rescue" (p. 209) and the implications this has for the daily routines of border work. While there are many ways of organizing this work (from formalized jobs in Nogales, Arizona to the mostly voluntary and autonomous bomberos in Nogales, Sonora), proximity to the suffering body produces shared possibilities of vulnerability for the emergency responder, both in terms of physical danger and of what Jusionyte calls "moral injury" (p. 27). This standpoint reveals the constructed nature of emergency as produced by the material and metaphorical effects of the border and the politics of security. What, then, does it mean to prioritize life in a (work)place that is composed so as to maim and kill? The notion of threshold put forward by Jusionyte points toward the literal entrance to the nation-state but also to the point at which something is transformed from one condition to another-where time and space mingle, when emergency becomes routine, where the real and the absurd converge.

\section{Author Bio}

Ishani Saraf is a PhD candidate in the Department of Anthropology at the University of California, Davis, with a Designated Emphasis in STS. She is currently completing her dissertation, "Scrap-scape: Waste, Trade, and Urban Ecologies in Contemporary Delhi." She has published on contesting urban landscapes through memories of work, new interfacial entities in Indian Ocean worlds, and infrastructures of the global circulation of scrap. 